
\title{
Z Research Suare \\ Amplicon-Based Analysis of the Fungal Diversity Across Kenyan Soda Lakes
}

Romano Mwirichia ( $\square$ mwirichia.romano@embuni.ac.ke)

University of Embu

\section{Research article}

Keywords: Haloalkaliphilic Fungi, Extremophiles, Amplicon Sequencing, Soda Lakes

Posted Date: October 27th, 2021

DOl: https://doi.org/10.21203/rs.3.rs-1001099/v1

License: (c) (i) This work is licensed under a Creative Commons Attribution 4.0 International License. Read Full License 


\section{Abstract}

\section{Background}

Microorganisms have been able colonize and thrive in environments characterized by low/high $\mathrm{pH}$, temperature, salt or pressure. Examples of extreme environments are the soda lakes and soda deserts. The objective of this study was to explore the fungal diversity across soda lakes Magadi, Elmenteita, Sonachi and Bogoria in Kenya. A new set of primers was designed to amplify a fragment long enough for the 454pyrosequencing technology.

\section{Results}

Analysis of the amplicons generated showed that the new primers amplified for eukaryotic groups. A total of 153,634 quality-filtered, non-chimeric sequences were used for community diversity analysis. The sequence reads were clustered into 502 operational taxonomic Units (OTUs) at $97 \%$ similarity using BLASTn analysis of which 432 were affiliated to known fungal phylotypes and the rest to other eukaryotes. Fungal OTUs were distributed across 107 genera affiliated to the phylum Ascomycota, Basidiomycota, Glomeromycotina and Incertae Sedis. The Phylum Ascomycota was the most abundant phylotype. Overall, fifteen (15) genera (Chaetomium, Monodictys, Arthrinium, Cladosporium, Fusarium, Myrothecium, Phyllosticta, Coniochaeta, Diatrype, Sarocladium, Sclerotinia, Aspergillus, Preussia and Eutypa) accounted for $65.3 \%$ of all the reads. The Genus Cladosporium was detected across all the samples at varying percentages with the highest being water from Lake Bogoria (51.4\%). Good's coverage estimator values ranged between 97 and 100\%, an indication that the dominant phylotypes were represented in the data.

\section{Conclusion}

These results provide useful insights that can guide cultivation dependent studies in order to understand the physiology and biochemistry of the as yet uncultured taxa.

\section{Introduction}

Microorganisms have been able to not only colonize but also thrive under unique or extreme environmental conditions characterizes by low/high $\mathrm{pH}$, temperature, salt or pressure. Examples of extreme environments are soda lakes which are characterized by high alkalinity (with $\mathrm{pH}$ values ranging between $9-12$ ) while $\mathrm{Na}^{+}$concentrations can reach saturation. Their surface area fluctuates due to extensive evaporation attributed to the intense sunlight and low levels of precipitation experienced where they are located. Despite the extreme physicochemical conditions in the soda lake ecosystems, a high level of species diversity has been reported (Lanzen et al., 2013; Oren A. 2008; Lozupone and Knight, 2007, Mesbah et al., 2007). These habitats exhibit higher productivity as compared to freshwater bodies (Grum-Grzhimaylo et al., 2016).

Whereas most of the studies on extremophiles have focused on prokaryotes, there are reports of alkaliphilic and alkalitolerant fungi isolated from soda lakes and soda soils in different parts of the world (Orwa et al., 2020; Grum-Grzhimaylo et al. 2013a; 2013b; Oren and Gunde-Cimerman, 2012). Different species of black 
yeast have been isolated from hyper-saline waters of solar saltans (Gunde-Cimeman et al., 2009; 2000). Different genera, including Cladosporium, Aspergillus, Penicillium, Alternaria and Acremonium sp. have been reported to exist as either moderately or weakly alkali tolerant species in saline environments (GrumGrzhimaylo et al., 2013b). Isolates affiliated to Chaetomium aureum, C. flavigenum, Emericella nidulans, and Eurotium amstelodami have previously been isolated from the Dead Sea (Buchalo et al., 2000). Orwa et al., (2020) describe isolates spread over 18 fungal genera namely Aspergillus, Penicillium, Acremonium, Phoma, Cladosporium, Septoriella, Talaromyces, Zasmidium, Chaetomium, Aniptodera, Pyrenochaeta, Septoria, Juncaceicola, Paradendryphiella, Sarocladium, Phaeosphaeria, Juncaceicola and Biatriospora from Lake Magadi in Kenya. Other reports include Chaetomium globosum from the Dead Sea as well as saline habitats of Wadi El-Natrun (Perl et al., 2018), Sarocladium kiliense from Lake Sonachi in Kenya (Ndwigah Fl, 2017).

High-throughput sequencing allows rapid estimation and identification of microorganisms without cultivation (Tedersoo et al., 2015). Using this apprach, a high prokaryotic and eukaryotic diversity has been reported from several alkaline lakes such as Magadi in Kenya (Salano et al.,2017; Kambura et al., 2016), Ethiopian soda lakes (Lanzén et al. 2013), Central European hypersaline lakes (Keresztes et al. 2012) and sediments from Tibetan Plateau (Xiong et al., 2012). Therefore, a sequence-based approach has made it easier to understand diversity and structure of microbial communities in diverse environments (Han et al., 2017; Valenzuela-Encinas et al., 2008). Most of the next-generation sequencing technologies used in diversity studies have an amplification step. The earliest polymerase chain reaction (PCR) primers to gain wide acceptance in fungal studies were for the Internal Transcribed Sequences (ITS) described by White et al., (1990) and thereafter modified by several researchers (Scoch et al., 2012; Martin, K.J., Rygiewicz, P.T., 2005; Gardes M and Bruns TD, 1993). However, these primers have been reported to have poor resolution at lower level (Cavender-Bares et al., 2009) or are not good at resolving taxonomic groups that have highly hypervariable ITS regions (Nilsson et al., 2016; Thiéry et al., 2016; Tedersoo et al., 2015; Schoch et al., 2012; Stockinger et al., 2010).

Besides the ITS region, the small and large subunits of the rRNA gene have been targeted for amplification in fungal diversity studies (Xue et al., 2019; Tedersoo et al., 2015). Several group-specific 18S rRNA gene primers have been reported (Lefevre et al., 2010; Lee J, Lee S,Young JPW, 2008; Lazarus KL and James TY, 2005). However, coverage as well as phylogenetic resolution to lower taxonomic levels is always a challenge especially when dealing with less explored habitats. In this study, we designed a new set of primers for next generation sequencing and tested them using different samples collected from different soda lakes in Kenya. The main objective was to explore whether fungal diversity varies between lakes Magadi, Elmenteita, Sonachi and Bogoria and across each lake due to differences physicochemical parameters. The study provides new insights on the spatial diversity across various soda lakes and with varying physicochemical parameters.

\section{Materials And Methods}

\section{Description of study Sites and sampling design}


Study sites chosen for the study were the hypersaline lake Magadi $\left(2^{\circ} 00^{\prime} S\right.$ and $\left.36^{\circ} 13^{\prime} \mathrm{E}\right)$ at an elevation of $600 \mathrm{~m}$ above sea level which lies in a naturally formed closed lake basin, an annual rainfall of approximately $500 \mathrm{~mm}$ (Behr and Röhricht, 2000). The lake covers an area of $90 \mathrm{~km}^{2}$ and evaporation is intense during the dry season. Lake Elmenteita $\left(0^{\circ} 27^{\prime} \mathrm{S}, 36^{\circ} 15^{\prime} \mathrm{E}\right)$ is a moderately saline lake located $1776 \mathrm{~m}$ above sea level and has no direct outlet. The lake is approximately $20 \mathrm{~km}^{2}$, but the total surface area changes with seasons often flooding during heavy rains. Lake Bogoria $\left(0^{\circ} 20^{\prime} \mathrm{N}\right.$ and $\left.36^{\circ} 15^{\prime} \mathrm{E}\right)$ lies at an altitude of $975 \mathrm{~m}$, low rainfall of $708 \mathrm{~mm}$ and has several geysers around the lake. The alkaline, saline crater lake Sonachi lies in a closed basin on the Eastern Rift valley $\left(0^{\circ} 49^{\prime} \mathrm{S}, 36^{\circ} 16^{\prime} \mathrm{E}\right)$.

\section{Sample collection and nucleic acid extraction}

Wet sediment, water samples, microbial mats, dry sediments and grassland soil were collected from lakes Bogoria, Elmenteita, Sonachi and Magadi as described (Orwa et al.,2020). $1 \mathrm{~g}$ of each soil or sediment sample was weighed into a sterile Eppendorf tube. For the water samples, $500 \mathrm{ml}$ was filtered through a $0.22 \mu \mathrm{M}$ filter, cut into small pieces with a sterile scalpel and transferred to a sterile $2 \mathrm{ml}$ tube. Total community deoxyribonucleic acid (DNA) was extracted using the phenol:chloroform protocol modified from Yeates et al., (1998). However, proteinase $\mathrm{K}$ was substituted with $6 \mathrm{M}$ Guanidine Isothiocyanate (GITC) for protein denaturation. Our experience has been that extraction of high molecular weight DNA from the soda lake samples using kits is problematic due to high salt content in the samples.

\section{Primer design and PCR amplification}

A total of 270 fungal sequences were downloaded from the SILVA database (Pruesse et al., 2007; Ludwig et al., 2004) and aligned using ClustalW v2.1 multiple sequence alignment tool (Larkin et al., 2007). A consensus sequence was generated using Jalview alignment (Waterhouse et al., 2009) and used to design the reverse primer using GeneFischer tool (Giegerich et al., 1996). Both primers were edited using the JalView alignement (Waterhouse et al., 2009) and tested using the Probe Match tool from Ribosomal database project (RDP) (Cole et al., 2007; 2009). The new primer pair amplifies a fragment of $712 \mathrm{bp}$ covering the V3, V4, V5 and V6 regions (Neefs et al., 1990) as well as partial V2 and V7 regions of the 18S rRNA gene. The designed primers are Fung_576f (5'-GCTCGTAGTTGAACCTTTGG-3') and Fung_975r (5'TCTGGACCTGGTGAGTTTC-3'). Thereafter the primers were modified for pyrosequencing by attaching an adaptor sequence, a key and a unique 12 Nucleotide MID for multiplexing purposes. Each PCR reaction $(50 \mu \mathrm{L})$ contained forward and reverse primers $(10 \mu \mathrm{M}$, each), dNTP's (10mM each), Phusion GC buffer (Finzymes), Phusion high fidelity polymerase $\left(0.5 \mathrm{U} / \mathrm{LL}^{-1}\right)$ and $25 \mathrm{ng}$ of template DNA. Cycling conditions were: initial denaturation at $98^{\circ} \mathrm{C}$ for 3 minutes followed by 25 cycles of denaturation at $94^{\circ} \mathrm{C}$ for $30 \mathrm{sec}$, annealing for $30 \mathrm{sec}$ at $58^{\circ} \mathrm{C}$, and extension at $72^{\circ} \mathrm{C}$ for $90 \mathrm{sec}$, and a final extension step of $72^{\circ} \mathrm{C}$ for 5 min. Amplification was confirmed by separating $2 \mu \mathrm{l}$ of the PCR product on a $1 \%$ agarose gel run for $1 \mathrm{~h}$ at 100 Volts. Later, three independent PCR products per sample were pooled in equal amounts, separated on a gel and extracted using the PeqGOLD gel extraction kit (PeqLab Biotechnologie GmbH, Erlangen, Germany). PCR products were quantified using a Nanodrop (PEQLAB Biotechnologie GmbH, Erlangen, Germany) and a Qubit fluorometer (Invitrogen $\mathrm{GmbH}$, Karlsruhe, Germany) as recommended by the manufacturers.

Sequencing of the PCR derived amplicons was performed on a Roche GS-FLX 454 pyrosequencer and 
Titanium chemistry (Roche, Mannheim, Germany). The raw sequence reads have been deposited into the SRA under the accession SRP019052.

\section{Sequence analysis}

Sequence reads were denoised and evaluated for potential chimeric sequences using UCHIME within the USEARCH package v.5.1 (Edgar et al., 2011). OTU picking was done from the quality filtered, denoised, nonchimeric sequences using a sequence identity cut-off of $97 \%$. Representative OTUs were picked using USEARCH v.5.1 (Edgar et al., 2011). Taxonomy was assigned to the representative sequences from each cluster by Basic Local Alignment Search Tool (BLAST) searches against the SILVA database v132 (Ludwig et al., 2004; Pruesse et al., 2007).

\section{Statistical analysis}

Rarefaction analysis using the script alpha_rarefaction.py in quantitative insights into microbial ecology (QIIME) v1.9.1 (Caporaso et al., 2010) was done to assess whether the sampling effort representative of the microbial diversity in the samples. OTUs were assigned to ecological guilds using the annotation tool FUNGuild (Nguyen et al., 2016). A heatmap to display the most abundant OTUs was created using Ampvis2 R package (Skytte et al., 2018). Diversity estimates (Good's coverage, Chao1 and Shannon) were generated using the alpha_diversity.py script in QIIME (Caporaso et al., 2010). The package "Indicspecies" (Cáceres, M. $D$ \& Legendre $P, 2009$ ) in R was used to find out if there are genera that significantly associate with different sample types. Nonmetric multidimensional scaling (NMDS) of fungal communities was conducted in $\mathrm{R}$ using the vegan package (Oksanen J, 2016), based on unweighted UniFrac (Lozupone et al., 2011) distance matrices.

\section{Results}

\section{Evaluation of the new primer set}

The newly designed primers amplified for eukaryotic groups only and no bacterial sequences were detected in this study. In each sample, the success rate for amplifying for fungal groups was above $90 \%$, which was good performance for environmental DNA. The amplicons could also be assigned to taxonomy with high confidence owing to the sequence length generated using the 454 technologies. In addition, the samples used ranged from dry sediments to microbial mats and therefore good quality DNA is key to amplification.

\section{Sequence data.}

The clean data from 32 samples comprised of 153,634 quality-filtered, denoised and non-chimeric sequences with no singletons. Based on BLASTn analysis, the sequences were clustered into 502 OTUs at $97 \%$ similarity; of which 432 were affiliated to known fungal phylotypes. Fungal OTUs per sample ranged from 13 in the Bogoria wet sediments (sample BWS10) to a high of 68 in the Dry sediments from Lake Sonachi (sample BDS10) as shown in Table 1.

\section{Diversity at the phylum level:}


The 432 fungal OTUs were distributed across 107 fungal genera affiliated to the phylum Ascomycota, Basidiomycota, Glomeromycotina and Incertae Sedis. 3\% of the sequences were clustered as unclassified fungal groups. The Phylum Ascomycota was the most dominant phylotype with the orders Capnodiales, Pleosporales, Hypocreales, Myrmecridiales, Sordariales and Xylariales being the most abundant. In this phylum, the order Pleosporales was the most diverse with 13 genera followed by the orders Capnodiales (9), Hypocreales (11) and Xylariales (11) that had 9 genera. Whereas the Ascomycota were the most abundant across the samples, we noted that in Elmenteita wet sediments the phylum Bacillariophytina accounted for $45 \%$ of the OTUs (Figure 1 ).

Sequences affiliated to Basidiomycota were detected in a few of the samples and were distributed in the orders Agaricales, Boletales, Polyporales, Cystofilobasidiales, Filobasidiales, Sporidiobolales and Malasseziales. The phylum Glomeromycotina was represented by a single genus Allomyces, in the species Allomyces macrogynus at $0.2 \%$ abundance in the Sonachi wet sediments. Overall, we identified fifteen (15) genera that constituted $65.3 \%$ of all the reads and these were Chaetomium, Monodictys, Arthrinium, Cladosporium, Fusarium, Myrothecium, Phyllosticta, Coniochaeta, Diatrype, Sarocladium, Sclerotinia, Aspergillus, Preussia, Eutypa. A further $20.2 \%$ of the OTUs that were affiliated to the order Pleosporales could not be identified below the order level. The Genus Cladosporium was detected across all the samples at varying percentages with the highest being water from Lake Bogoria (51.4\%).

\section{Diversity across the different samples}

We evaluated and compared the diversity across the 32 samples. We used different metrics (Richness, Simpson, Shannon, Evenness, Fisher and Good's coverage) to evaluate the alpha diversity across the samples. Good's coverage estimator values were between 97 and 100\% (Table 1). This is an indication that the dominant phylotypes were represented in the data. This was even more evident when the samples were clustered by sample type $(P=0.05)$. The lowest diversity was in the brine samples and the highest in the sediment samples (Fig. 3).

\section{Differences in fungal diversity across the lakes.}

Bray Curtis dissimilarity analysis (Fig. 4a) demonstrated that the samples were separated into 3 clusters. The samples from Lake Bogoria formed a distinct cluster. This could be due to differences in OTU composition. For example, no OTUs related to the genus Cladosporium were detected in samples from Lake Bogoria, whereas the genus Myrothecium, Sclerotinia, Lasiodiplodia, and Peziza were only identified in Lake Bogoria samples (Supplementary Table S1).

Indicator species analysis identified 5 OTUs affiliated to the genus Ochroconis $(\mathrm{p}=0.01)$, Aspergillus $(\mathrm{p}=$ $0.01)$, Cladosporium $(p=0.01)$ and Sarocladium $(p=0.001)$ as key species in the brine samples only. Using FUNGuild, $63.6 \%$ of the fungal OTUs were classified according to their trophic mode as either saprotroph (32\%), pathotrophs (19\%) or to symbiotrophs ( $9 \%)$. The rest were classified as Saprotroph-Symbiotroph (2\%), Pathotroph-Symbiotroph (4\%), Pathotroph-Saprotroph (7\%) and Pathotroph-Saprotroph-Symbiotroph $(28 \%)$. 


\section{Discussion}

The overall diversity and significance of fungal communities in the soda lakes has not been understood owing the limited data available as compared to bacteria. The Kenyan soda lakes are in geographically remote areas that experience intense solar radiation; evaporation rates exceed precipitation rates hence there is concentration of salts which contributes to the elevated salinity levels. This may be one of the reasons why they are not well explored. The diversity reported so far has been based on culture dependent studies (Orwa et al., 2020; Solano et al., 2018; Bondarenko, S.A., Georgieva, M.L. and Bilanenko, E.N., 2018) or using molecular approaches (Solano et al., 2017). Amplicon sequencing provides a better and detailed understanding of the fungal diversity in these unique habitats. Out of the 432 fungal OTUS, 389 were assigned taxonomy to genus level while 320 could be identified to the species level. Additionally, $3 \%$ of the fungi detected could not be classified and may represent novel autochthonous soda lake fungal phylotypes. There are reports that a major percentage of the observed species in diversity studies are tagged as uncultured (Harris et al., 2013; Schneider et al., 2013; Mwirichia et al., 2010; 2009; Ley et al., 2006). This necessitates more isolation efforts in order to understand the physiology and metabolism of these novel groups.

In this study, the phylum Ascomycota accounted for more than $80 \%$ of the reads across the sample, with the most abundant subphylum being Dothideomycetes, followed by Sordariomycetes, Leotiomycetes, Eurotiomycetes, and Pezizomycetes. Sharma et al., (2016) reported that $98 \%$ of the isolates recovered from Lonar lake belonged to Ascomycota, sub-phylum Pezizomycotina. The Ascomycetes have also been reported to be dominant in marine sediments of Kongsfjorden, Svalbard (Zhang et al., 2015), constituting $54.8 \%$ of the OTUs. In marine sediments of Arabian Sea, Ascomycota were reported to be the most abundant phylum at $83 \%$ and the rest (17\%) were Zygomycota (Soumya et al., 2013). However, Basidiomycota have been reported to be dominant in other hypersaline environments (Singh et al. 2011; Bass et al., 2007). The Genus Cladosporium was detected across all the samples with the highest relative abundance being in water from Lake Bogoria (51.4\%). However, some of the phylotypes (Cladosporium sphaerospermum, Fusarium sp., and Penicillium sp.) have also been observed in marine sediments (Zhang et al., 2013; Soumya et al., 2013; Samuel et al., 2011). Chaetomium globosum has been isolated from the Dead Sea as well as saline habitats of Wadi El-Natrun (Perl et al., 2018) while isolates with close similarity to Sarocladium kiliense were recovered Lake Sonachi sediments by (Ndwigah FI 2017). Salinity as well as $\mathrm{pH}$ affects fungal growth and spore formation which in turn may affect the overall diversity (Grumgrzhimaylo et al., 2016). Production of extremolytes and extremozymes or accumulation of $\mathrm{K}$ ions and compatible organic solutes in the cells are ways of coping with osmotic stress (Raddadi et al., 2018; Plemenita_s et al., 2014; Roberts, 2005). Unique features such as the thick mycelium observed in Phoma herbarum are important in stress tolerance while pigments such as those produced by Zasmidium cellare, Aspergillus keveii, and Cladosporium velox enable them to thrive in the harsh environments (Liu et al., 2018; Orwa et al., 2020).

A key ecological question is whether the observed fungal groups originate from the terrestrial environment via runoff or are actual residents exclusive to the soda lake habitats. It is possible that run-off from the surrounding soil introduces spores into the lakes and which over time adapt to the haloalkaline 
environment. Previous culture dependent studies (Orwa et al., 2020) on Lake Magadi recovered isolates spread over fungal genera namely Aspergillus, Penicillium, Acremonium, Phoma, Cladosporium, Septoriella, Talaromyces, Zasmidium, Chaetomium, Aniptodera, Pyrenochaeta, Septoria, Juncaceicola, Paradendryphiella, Sarocladium, Phaeosphaeria, Juncaceicola and Biatriospora. These isolates grew better when lake water was used in media preparation as compared to synthetic mineral medium. Pawar, V. H. \& Thirumalachar, (1966) observed differential growth between marine and terrestrial organisms of the same species. Those of marine origin grew better on seawater agar as compared to the terrestrial isolates that grew better on non-seawater agar. In summary, the diversity and function of most fungal taxa in the soda lake ecosystem remains poorly understood and therefore, a combination of traditional culture-based method and metatranscriptomics may help to answer important ecological questions.

\section{Conclusions}

The findings from this study indicate that the soda lakes habits host diverse fungal communities that have adapted to the extreme physicochemical conditions in the lakes. This is supported by the occurrence of same taxa in lakes that are geographically separated. The findings will be a valuable resource that will guide culture dependent studies while the data will be valuable for comparative studies.

\section{Declarations}

Ethical Approval and Consent to participate: Not Applicable

Consent for publication: The author gives consent for publication

Availability of data and material: The raw sequence reads have been deposited into the SRA under the accession SRP019052.

Competing interests: The author declares no conflict of Interest

Funding: Not Applicable

Authors' contributions: RM conceived the experiments, did the experiments, analyzed the data, wrote the manuscript

Acknowledgements: The Alexander von Humboldt Stiftung for a Postdoctoral Fellowship under the Georg Foster Fellowship Program; The Göttingen Genomics Laboratory for generating the Amplicons.

\section{Authors' information:}

Affiliation

\section{University of Embu, Kenya}

Romano Mwirichia 


\section{References}

1. Lanzen A, Simachew A, Gessesse A, Chmolowska D, Jonassen I, Øvreås L. Surprising Prokaryotic and Eukaryotic Diversity, Community Structure and Biogeography of Ethiopian Soda Lakes. PloS one. 2013; 8. e72577. 10.1371/journal.pone.0072577.

2. Oren A (2008) Microbial life at high salt concentrations: phylogenetic and metabolic diversity. Saline systems, 4(1), 1-13.

3. Lozupone CA, Knight R. Species divergence and the measurement of microbial diversity FEMS Microbiology Reviews. 2008; 1;32(4):557-78.

4. Lozupone CA Knight R. Global patterns in bacterial diversity. Proc Natl Acad Sci USA. 2007; 104: 11436-11440.

5. Mesbah N, Abou-El-Ela S, Wiegel J. Novel and Unexpected Prokaryotic Diversity in Water and Sediments of the Alkaline, Hypersaline Lakes of the Wadi An Natrun, Egypt. Microbial Ecology. 2007; 54: 598-617.

6. Grum-grzhimaylo AA, Georgieva ML, Bilanenko EN. On the diversity of fungi from soda soils,. Fungal Divers. 2016; 76: 27-74.

7. Orwa P, Mugambi G, Wekesa V, Mwirichia R. Isolation of haloalkaliphilic fungi from Lake Magadi in Kenya. Heliyon. 2020; 6(1), p.e02823.

8. Grum-Grzhimaylo AA, Debets AJM, van Diepeningen AD, Georgieva ML, Bilanenko EN. Sodiomyces alkalinus, a new holomorphic alkaliphilic ascomycete within the Plectosphaerellaceae. Persoonia: Molecular Phylogeny and Evolution of Fungi. (2013a) 31, 147.

9. Grum-Grzhimaylo AA, GeorgievaML, Debets AJ, Bilanenko EN. Are alkalitolerant fungi of the Emericellopsis lineage (Bionectriaceae) of marine origin? IMA Fungus. 2013b; 4:213228.doi:10.5598/imafungus.2013. 04.02.07

10. Oren A, Gunde-Cimerman N. Fungal life in the Dead Sea. In: Raghukumar C. Biology of Marine Fungi, editors. Berlin Heidelberg: Springer-Verlag; 2012. p.115-132.

11. Gunde-Cimerman N, Ramos J, Plemenitaš A. Halotolerant and halophilic fungi. Mycological research. 2009; 1: 113(11):1231-41.

12. Gunde-Cimerman N, Zalar P, de Hoog S, Plemenitaš A. Hypersaline waters in salterns-natural ecological niches for halophilic black yeasts. FEMS microbiology Ecology. 2000; 1:32 (3):235-40.

13. Buchalo AS, Nevo E, Wasser SP, Volz PA. Newly discovered halophilic fungi in the Dead Sea (Israel). In Journey to diverse microbial worlds. Springer, Dordrecht; 2000; p. 239-252.

14. Perl T, Kis-Papo T, Nevo EFungal biodiversity in the hypersaline Dead Sea: extinction and evolution. Biological Journal of the Linnean Society. 2017; 1:121(1):122-32.

15. Ndwigah Fl. Characterization, Identification and Metabolites of Fungi from the soda lakes in Kenya. Doctoral dissertation, 2017; COHES-JKUAT.

16. Tedersoo L, Anslan S, Bahram M, Pólme S, Riit T, Liiv I, et al. Shotgun metagenomes and multiple primer pair-barcode combinations of amplicons reveal biases in metabarcoing analyses of fungi. 
MycoKeys. 2015; 10: 1- 43. doi: 10.3897/mycokeys.104852

17. Salano OA, Makonde HM, Kasili RW, Wangai LN, Nawiri MP, Boga HI. Diversity and distribution of fungal communities within the hot springs of soda lakes in the Kenyan rift valley. African Journal of Microbiology Research. 2017; 11(19):764 -75.

18. Kambura A, Mwirichia R, Kasili R, Karanja EN, Makonde H, Boga HI. Diversity of fungi in sediments and water sampled from the hot springs of Lake Magadi and Little Magadi in Kenya. African Journal of Microbiological Research. 2016; 09.12.15/7879.

19. Keresztes ZG, Felföldi T, Somogyi B, Székely G, Dragoş N, Márialigeti K, Bartha C, Vörös L. First record of picophytoplankton diversity in Central European hypersaline lakes. Extremophiles. 2012; 16:759769.

20. Xiong J, Liu Y, Lin X, Zhang H, Zeng J, Hou J, Yang Y, Yao T, Knight R, Chu H. Geographic distance and $\mathrm{pH}$ drive bacterial distribution in alkaline lake sediments across Tibetan Plateau. Environ Microbiol. 2012; 14:2457-2466.

21. Han R, Zhang X, Liu J, Long QF, Chen LS, Liu DL et al. Microbial community structure and diversity within hypersaline keke salt lake environments. Can. J. Microbiol. 2017; 63, 895-908. doi: 10.1139/cjm-2016-0773

22. Valenzuela-Encinas C, Neria-Gonzalez I, Alcantara-Hernandez RJ, Enriquez-Aragon JA, EstradaAlvarado I, Hernandez-Rodriguez C, et al. Phylogenetic analysis of the archaeal community in an alkaline-saline soil of the former lake Texcoco (Mexico). Extremophiles. 2008; 12: 247-254. doi: 10.1007/s00792-007-0121-y

23. White TJ, Bruns T, Lee SJ, Taylor J. Amplification and direct sequencing of fungal ribosomal RNA genes for phylogenetics. PCR protocols: a guide to methods and applications. 1990;18(1):315-22.

24. Schoch CL, Seifert KA, Huhndorf S, Robert V, Spouge JL, Levesque CA, Chen W. Fungal Barcoding Consortium. Nuclear ribosomal internal transcribed spacer (ITS) region as a universal DNA barcode marker for Fungi. Proceedings of the National Academy of Sciences. 2012; 109(16):6241-6.

25. Thiéry O, Vasar M, Jairus T, Davison J, Roux C, Kivistik PA et al. Sequence variation in nuclear ribosomal small subunit, internal transcribed spacer and large subunit regions of Rhizophagus irregularis and Gigaspora margarita is high and isolate-dependent. Mol. Ecol. 2016; 25: 2816-2832. doi: $10.1111 / \mathrm{mec} .13655$

26. Martin KJ, Rygiewicz PT. Fungal-specific PCR primers developed for analysis of the ITS region of environmental DNA extracts. BMC Microbiology. 2005; 5: 28 Doi.org/10.1186/1471-2180-5-28

27. Gardes M, Bruns TD. ITS primers with enhanced specificity for basidiomycetes - application to the identification of mycorrhizae and rusts. Mol Ecol. 1993; 2: 113-118.

28. Cavender-Bares J, Kozak K, Fine PVA, Kembel SW. The merging of community ecology and phylogenetic biology Ecol Lett. 2009; 12: 693-715. doi: 10.1111/j.1461-02548.2009.01314.x

29. Nilsson RH, Wurzbacher C, Bahram M, Coimbra VRM, Larsson E, Tedersoo L, et al. Top 50 most wanted fungi. Mycokeys. 2016; 12: 29 - 40. 
30. Stockinger $H$, Krüger $M$, Schüssler $A$. DNA barcoding of arbuscular mycorrhizal fungi. New Phytol. 2010; 187:461-474. doi: 10.111/j.1469-8137.2010.03262.x

31. Xue C, Hao Y, Pu X, Penton C, Wang Q, Zhao M, et al. Effect of LSU and ITS genetic markers and reference databases on analyses of fungal communities. Biol. Fert. Soils. 2019; 55: 79-88. doi: $10.1007 /$ s00374-018-1331-4

32. Lefevre E, Jobard M, Venisse JS, Bec A, Kagami M, Amblard C, et al. Development of a real-time PCR assay for quantitative assessment of uncultured freshwater zoosporic fungi. J Microbiol Methods. 2010; 81(1):69-76.

33. Lee J, Lee S, Young JPW. Improved PCR primers for the detection and identification of arbuscular mycorrhizal fungi. FEMS Microbiol Ecol. 2008; 65(2):339-49.

34. Lazarus KL, James TY. Surveying the biodiversity of the Cryptomycota using a targeted PCR approach. Fungal Ecol. 2015; 14:62-70.

35. Behr HJ, Röhricht C. Record of seismotectonic events in siliceous cyanobacterial sediments (Magadi cherts), Lake Magadi, Kenya. International Journal of Earth Sciences. 2000; 89(2):268-83.

36. Yeates $C$, Gillings MR, Davison AD, Altavilla N, Veal DA. Methods for microbial DNA extraction from soil for PCR amplification. Biological procedures online. 1998; 1(1):40-7.

37. Pruesse E, Quast C, Knittel K, Fuchs BM, Ludwig W, Peplies J, Glöckner FO. SILVA: a comprehensive online resource for quality checked and aligned ribosomal RNA sequence data compatible with ARB. Nucleic acids research. 2007; 1:35(21):7188-96.

38. Ludwig W, Strunk O, Westram R, Richter L, Meier H, Yadhukumar, Buchner A, Lai T, Steppi S, Jobb G, Förster W. ARB: a software environment for sequence data. Nucleic acids research. 2004; 15:32(4):1363-71.

39. Larkin MA, Blackshields G, Brown NP, Chenna R, McGettigan PA, McWilliam H, Valentin F, Wallace IM, Wilm A, Lopez R, Thompson JD. Clustal W and Clustal X version 2.0. bioinformatics. 2007; 23(21):2947-8.

40. Waterhouse AM, Procter JB, Martin DM, Clamp M, Barton GJ. Jalview Version 2-a multiple sequence alignment editor and analysis workbench. Bioinformatics. 2009; 25(9):1189-91.

41. Giegerich R, Meyer F, Schleiermacher C. GeneFisher-software support for the detection of postulated genes. InISMB. 1996; 4: 68-77.

42. Cole JR, Chai B, Farris RJ, Wang Q, Kulam-Syed-Mohideen AS, McGarrell DM et al. The ribosomal database project (RDP-II): Introducing myRDP space and quality controlled public data. Nucleic acids research. 2007; 35(1):169-72.

43. Cole JR, Wang Q, Cardenas E, Fish J, Chai B, Farris RJ, Kulam-Syed-Mohideen AS et al. The Ribosomal Database Project: improved alignments and new tools for rRNA analysis. Nucleic acids research. 2009; 37(1):141-5.

44. Neefs JM, Van de Peer Y, Hendriks L, De Wachter R. Compilation of small ribosomal subunit RNA sequences. Nucleic acids research. 1990; 18(I):2237. 
45. Edgar RC, Haas BJ, Clemente JC, Quince C, Knight R. UCHIME improves sensitivity and speed of chimera detection. Bioinformatics. 2011; 27(16):2194-200.

46. Caporaso JG, Kuczynski J, Stombaugh J, Bittinger K, Bushman FD, Costello EK et al. QIIME allows analysis of high-throughput community sequencing data. Nature methods. 2010; 7(5): 335-336.

47. Nguyen NH, Song Z, Bates ST, Branco S, Tedersoo L, Menke J, Schilling JS, Kennedy PG. FUNGuild: an open annotation tool for parsing fungal community datasets by ecological guild. Fungal Ecology. 2016; 20: 241-248.

48. Skytte KA, Kirkegaard RH, Karst SM, Albertsen M. Ampvis2: an R package to analyse and visualise $16 \mathrm{~S}$ rRNA amplicon data. BioRxiv. 2018;

49. Cáceres MD, Legendre P. Associations between species and groups of sites: indices and statistical inference. Ecology. 2009;90: 3566-3574

50. Oksanen J. Package 'vegan'-Community Ecology Package, version 2.0-4. 2016.

51. Lozupone C, Lladser ME, Knights D, Stombaugh J, Knight R. UniFrac: an effective distance metric for microbial community comparison. The ISME journal. 2011; 5(2): 169 -172.

52. Salano OA, Makonde HM, Kasili RW, Boga HI. Isolation and characterization of fungi from a hot-spring on the shores of Lake Bogoria, Kenya. Journal of Yeast and Fungal Research. 2018; 9(1): 1-13.

53. Bondarenko SA, Georgieva ML, Bilanenko EN. Fungi inhabiting the coastal zone of Lake Magadi. Contemporary Problems of Ecology. 2018; 11(5), pp.439-448.

54. Harris JK, Caporaso JG, Walker JJ, Spear JR, Gold NJ, Robertson CE, et al. Phylogenetic stratigraphy in the Guerrero Negro hypersaline microbial mat. ISME J. 2013; 7:50-60.

55. Schneider D, Arp G, Reimer A, Reitner J, Daniel R. Phylogenetic analysis of a microbialite-forming microbial mat from a hypersaline lake of the Kiritimati atoll, Central Pacific. PLoS One. 2013; 8:e66662.

56. Mwirichia R, Muigai AW, Cousin S, Boga HI, Stackebrandt E. Bacterial Diversity in the Haloalkaline Lake Elmenteita in Kenya. Current Microbiology. 2011; 62:209-221. DOI:10.1007/s00284-010-9692-4).

57. Mwirichia R, Muigai AW, Cousin S, Boga HI, Stackebrandt E. Archaeal diversity in the haloalkaline Lake Elmenteita in Kenya. Current Microbiology. 2010; 60: 47-52.

58. Ley RE, Harris JK, Wilcox J, Spear JR, Miller SR, Bebout BM. Unexpected diversity and complexity of the Guerrero Negro hypersaline microbial mat. Appl Environ Microbiol. 2006; 72:3685-3695.

59. Sharma R, Prakash O, Sonawane MS, Nimonkar Y, Golellu PB, Sharma R. Diversity and Distribution of Phenol Oxidase Producing Fungi from Soda Lake and Description of Curvularia lonarensis sp. nov. Frontiers in microbiology. 2016; 7.

60. Zhang T, Wang NF, Zhang YQ, Liu HY, Yu LY. Diversity and distribution of fungal communities in the marine sediments of Kongsfjorden, Svalbard (High Arctic). Scientific reports. 2015; 5(1): 1-11.

61. Soumya KS, Jacob JC, Correya S, Smitha SL, Ramya KD, Anil Kumar PR, Thomas M, Philip R. Filamentous fungal isolates from the continental shelf and slope sediments of Arabian Sea. Int J Res Marine Sci. 2013; 2:26-32. 
62. Singh P, Raghukumar C, Verma P, Shouche Y. Fungal community analysis in the deep-sea sediments of the Central Indian Basin by culture-independent approach. Microb. Ecol. 2011; 61: 507-517

63. Bass D, Howe A, Brown N, Barton H, Demidova M, Michelle H, Li L, Sanders H, Watkinson SC, Willcock S, Richards TA. Yeast forms dominate fungal diversity in the deep oceans. Proceedings of the Royal Society B: Biological Sciences. 2007; 274(1629): 3069-3077.

64. Zhang XY, Zhang Y, Xu XY, Qi SH. Diverse deep-sea fungi from the South China Sea and their antimicrobial activity. Current Microbiol.2013; 67: 525-530.

65. Samuel P, Prince L, Prabakaran P. Assessment of mycological diversity of marine sediment of south east coast of Tamilnadu, India. Euro. J. Exp. Bio. 2011; 1: 130-138

66. Raddadi, Noura, Cherif, Ameur, Daffonchio, Daniele, Neifar, Mohamed, Fava F. Biotechnological Applications of Extremophiles, Extremozymes and Extremolytes. Applied microbiology and biotechnology. 2015; 99(19):7907-13.

67. Plemenitaš A, Vaupotič T, Lenassi M, Kogej T, Gunde-Cimerman N. Adaptation of extremely halotolerant black yeast Hortaea werneckii to increased osmolarity: a molecular perspective at a glance. Studies in Mycology. 2008; 61:67-75.

68. Roberts MF. Organic compatible solutes of halotolerant and halophilic microorganisms. Saline Syst. 2005; 1(1): 5 .

69. Liu K, Ding X, Wang HF, Zhang X, Hozzein WN, Wadaan MAM, Lan A, Zhang B, Li W. Eukaryotic microbial communities in hypersaline soils and sediments form the alkaline hypersaline Huama Lake as revealed by 454 pyrosequencing. Antonie Van Leeuwenhoek. 2014; 105:871-880.

70. Pawar VH, Thirumalachar MJ. Studies on halophilic soil fungi from Bombay. Nova Hedwigia. 1966; $12: 497-508$

\section{Tables}

Table 1: Summary description of the 33 samples investigated and their diversity indices. The samples are sorted by study site. BW, EW and SW denote water samples from Bogoria, Elmenteita and Sonachi respectively; BWS, EWS, MWS and SWS denote wet sediments samples from Bogoria, Elmenteita, Magadi and Sonachi respectively; EDS, SDS denote dry sediments from Elmenteita and Sonachi respectively; BM and EM denote Microbial mats from Bogoria and Elmenteita respectively while MBR and MSC denotes brine and salt crust from Magadi; BGS, EGS and SGS denote grassland soils from Bogoria, Elmenteita and Sonachi respectively. 


\begin{tabular}{|c|c|c|c|c|c|c|c|c|c|c|c|}
\hline imple & Lake & Sample type & $\mathrm{pH}$ & $\begin{array}{l}\text { Temp. } \\
\left({ }^{\circ} \mathrm{C}\right)\end{array}$ & $\begin{array}{l}\text { Total No. } \\
\text { of } \\
\text { Sequences }\end{array}$ & $\begin{array}{l}\text { Fungal } \\
\text { Sequences }\end{array}$ & $\begin{array}{l}\% \text { of fungal } \\
\text { sequences }\end{array}$ & $\begin{array}{l}\text { Total } \\
\text { No. } \\
\text { of } \\
\text { OTUs }\end{array}$ & $\begin{array}{l}\text { Fungal } \\
\text { OTUs }\end{array}$ & Chao1 & $\begin{array}{l}\text { Good's } \\
\text { coverage }\end{array}$ \\
\hline JS & Bogoria & Wet_sediments & 7.6 & 34 & 2,340 & 2,320 & 99.15 & 47 & 47 & 41.75 & 0.99 \\
\hline 3S & Bogoria & Grassland_soil & 7.6 & 24 & 661 & 658 & 99.55 & 26 & 22 & 24.00 & 1.00 \\
\hline MM & Bogoria & Mats & 7.6 & 72 & 1,073 & 1,073 & 100.00 & 21 & 21 & 22.60 & 0.99 \\
\hline N1 & Bogoria & Water & 7.6 & 88 & 3,401 & 3,394 & 99.79 & 39 & 30 & 34.00 & 0.98 \\
\hline N2 & Bogoria & Water & 10.1 & 28 & 1,467 & 1,446 & 98.57 & 34 & 28 & 28.00 & 0.99 \\
\hline NS1 & Bogoria & Wet_sediments & 7.6 & 24.3 & 736 & 735 & 99.86 & 20 & 17 & 17.00 & 1.00 \\
\hline NS2 & Bogoria & Wet_sediments & 7.6 & 27 & 1,103 & 1,093 & 99.09 & 21 & 18 & 18.00 & 1.00 \\
\hline NS3 & Bogoria & Wet_sediments & 7.6 & 30.6 & 747 & 747 & 100.00 & 15 & 15 & 15.00 & 1.00 \\
\hline NS4 & Bogoria & Wet_sediments & 7.6 & 42.6 & 1,612 & 1,601 & 99.32 & 34 & 32 & 30.00 & 0.99 \\
\hline NS5 & Bogoria & Wet_sediments & 7.6 & 55.8 & 764 & 756 & 98.95 & 23 & 19 & 20.00 & 1.00 \\
\hline NS6 & Bogoria & Wet_sediments & 7.6 & 68.1 & 1,032 & 1,029 & 99.71 & 23 & 20 & 19.25 & 1.00 \\
\hline NS8 & Bogoria & Wet_sediments & 7.6 & 76.1 & 2,637 & 2,592 & 98.29 & 41 & 37 & 39.50 & 0.99 \\
\hline NS9 & Bogoria & Wet_sediments & 7.6 & 44.6 & 2,067 & 2,052 & 99.27 & 30 & 28 & 36.00 & 0.98 \\
\hline NS10 & Bogoria & Wet_sediments & 7.6 & 35.8 & 596 & 595 & 99.83 & 14 & 13 & 13.00 & 1.00 \\
\hline NS12 & Bogoria & Wet_sediments & 10.1 & 72 & 3369 & 3,338 & 99.08 & 47 & 39 & 36.00 & 0.99 \\
\hline JS & Elmenteita & Dry_sediments & 9.9 & 24 & 18,264 & 18,108 & 99.15 & 78 & 60 & 52.43 & 0.98 \\
\hline 3S & Elmenteita & Grassland_soil & 9.9 & 24 & 8,177 & 8,148 & 99.65 & 62 & 59 & 64.00 & 0.97 \\
\hline $\mathbf{M}$ & Elmenteita & Mats & 9.9 & 65 & 6,745 & 6,732 & 99.81 & 65 & 58 & 48.43 & 0.98 \\
\hline N1 & Elmenteita & Water & 9.9 & 65 & 12,992 & 12,881 & 99.15 & 52 & 46 & 38.75 & 0.99 \\
\hline$N 2$ & Elmenteita & Water & 8.7 & 24 & 6,776 & 6,746 & 99.56 & 58 & 45 & 45.25 & 0.98 \\
\hline NS & Elmenteita & Wet_sediments & 9.9 & 22.7 & 15,612 & 15,598 & 99.91 & 68 & 40 & 46.00 & 0.98 \\
\hline BR & Magadi & Brine & 10.3 & 37.4 & 9,988 & 9,928 & 99.40 & 51 & 47 & 37.88 & 0.99 \\
\hline M1 & Magadi & Mats & 9.4 & 44.9 & 522 & 520 & 99.62 & 27 & 23 & 26.17 & 1.00 \\
\hline $\mathrm{SC}$ & Magadi & Salt_Crust & 10.3 & 47.2 & 1,181 & 1,174 & 99.41 & 40 & 34 & 39.00 & 0.99 \\
\hline WS1 & Magadi & Wet_sediments & 9.4 & 44.9 & 1,062 & 1,052 & 99.06 & 40 & 39 & 38.60 & 0.99 \\
\hline WS2 & Magadi & Wet_sediments & 9.4 & 44.9 & 585 & 582 & 99.49 & 28 & 26 & 27.25 & 1.00 \\
\hline WS3 & Magadi & Wet_sediments & 8.5 & 38 & 12,121 & 12,121 & 100.00 & 39 & 39 & 33.50 & 0.99 \\
\hline WS4 & Magadi & Wet_sediments & 9.4 & 85 & 11,499 & 11,481 & 99.84 & 73 & 64 & 62.00 & 0.97 \\
\hline JS & Sonachi & Wet_sediments & 9.9 & 26.9 & 1,561 & 1,538 & 98.53 & 81 & 68 & 66.59 & 0.97 \\
\hline iS & Sonachi & Grassland_soil & 9.9 & 26.9 & 7,608 & 7,571 & 99.51 & 72 & 63 & 56.11 & 0.97 \\
\hline$N$ & Sonachi & Water & 9.9 & 26.9 & 5,400 & 5,370 & 99.44 & 59 & 48 & 39.14 & 0.99 \\
\hline NS & Sonachi & Dry_sediments & 9.9 & 26.9 & 9,936 & 9,855 & 99.18 & 52 & 43 & 39.50 & 0.98 \\
\hline
\end{tabular}

\section{Supplementary Table}

Supplementary Table S1 is not available with this version.

Figures 


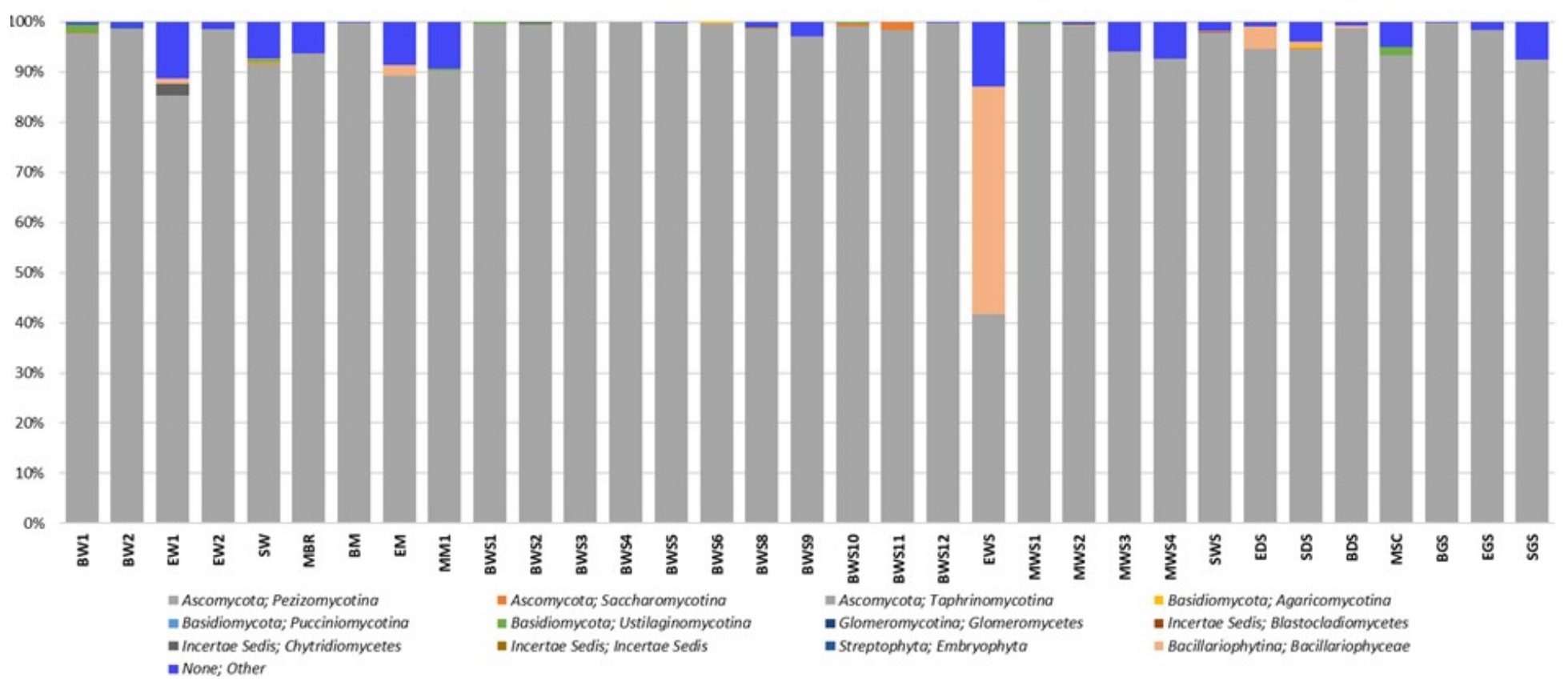

\section{Figure 1}

Distribution of OTUs at the Class level across the 33 samples analyzed in this study.

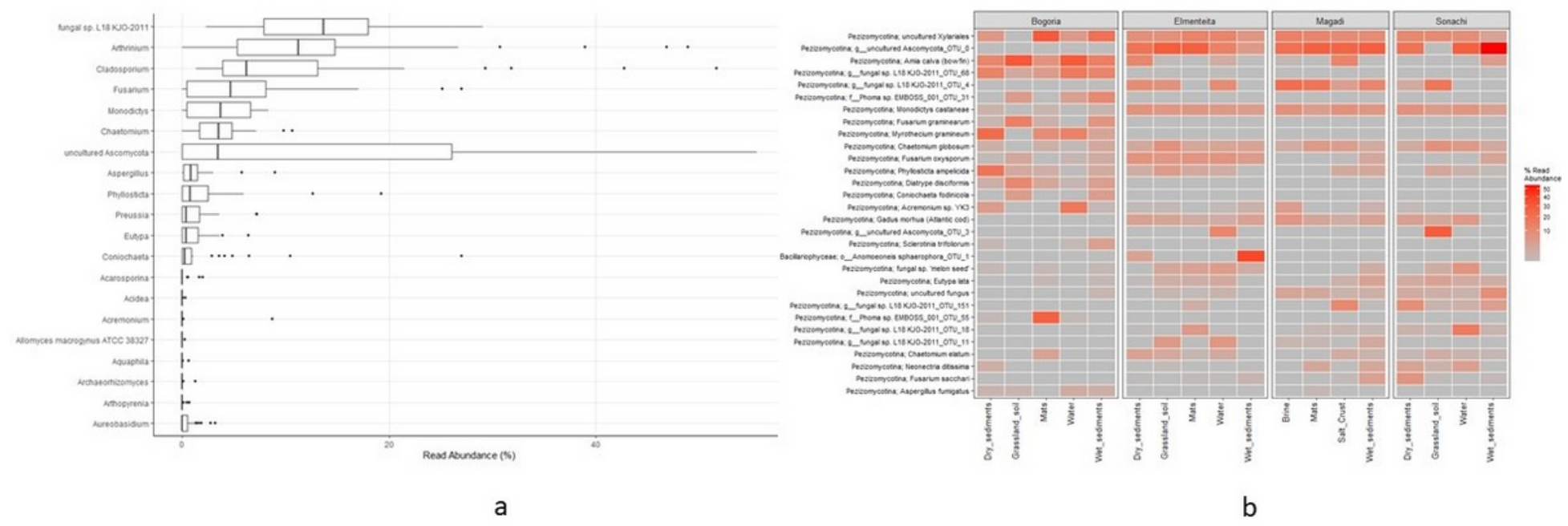

Figure 2

a) Percentage read abundance of the top 20 species across the samples. b) Heatmap showing the \% abundance of the top 30 phylotypes. 


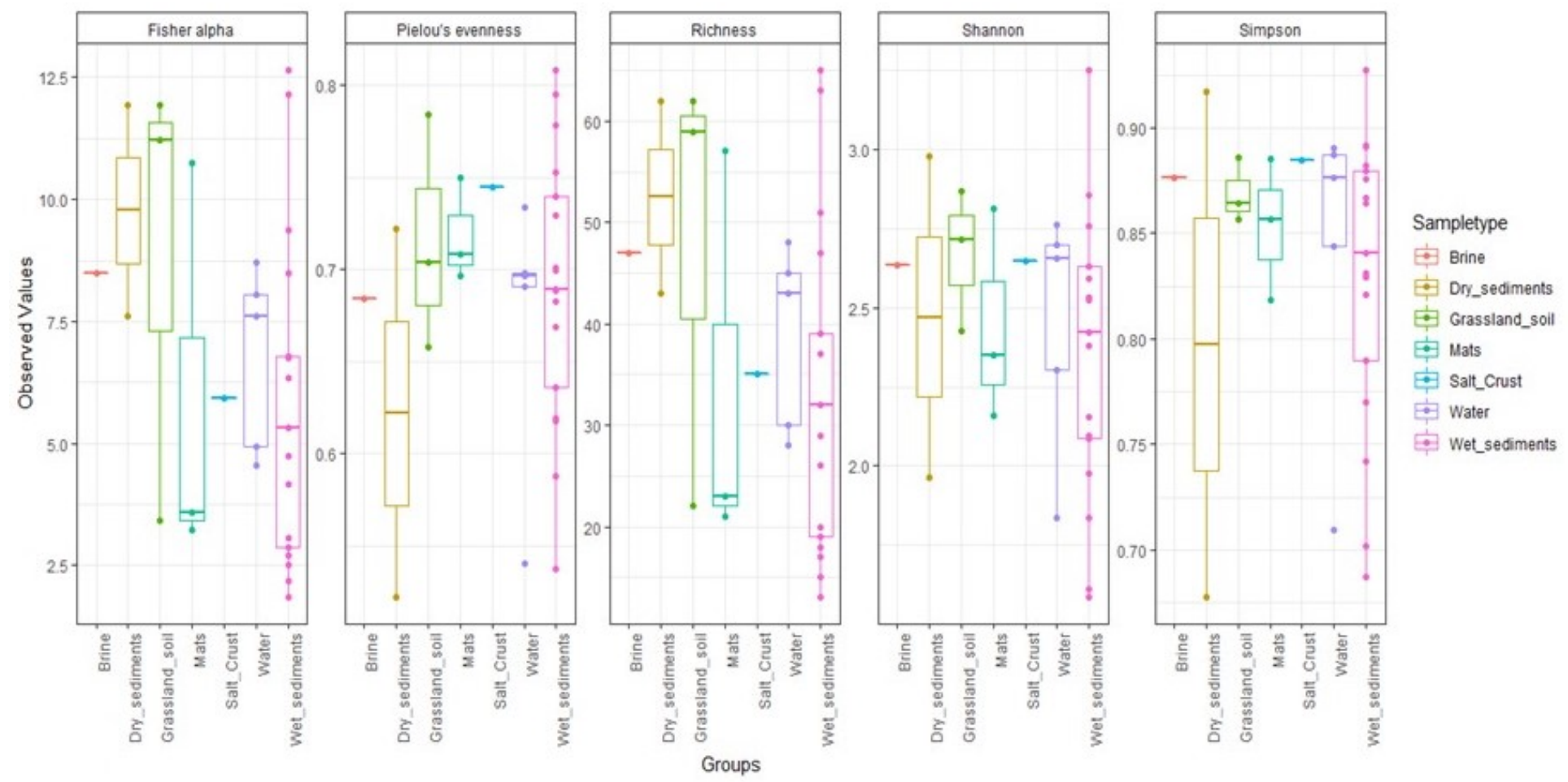

Figure 3

Alpha Diversity indices across the samples based on Richness, Simpson, Shannon, Evenness and Fisher.

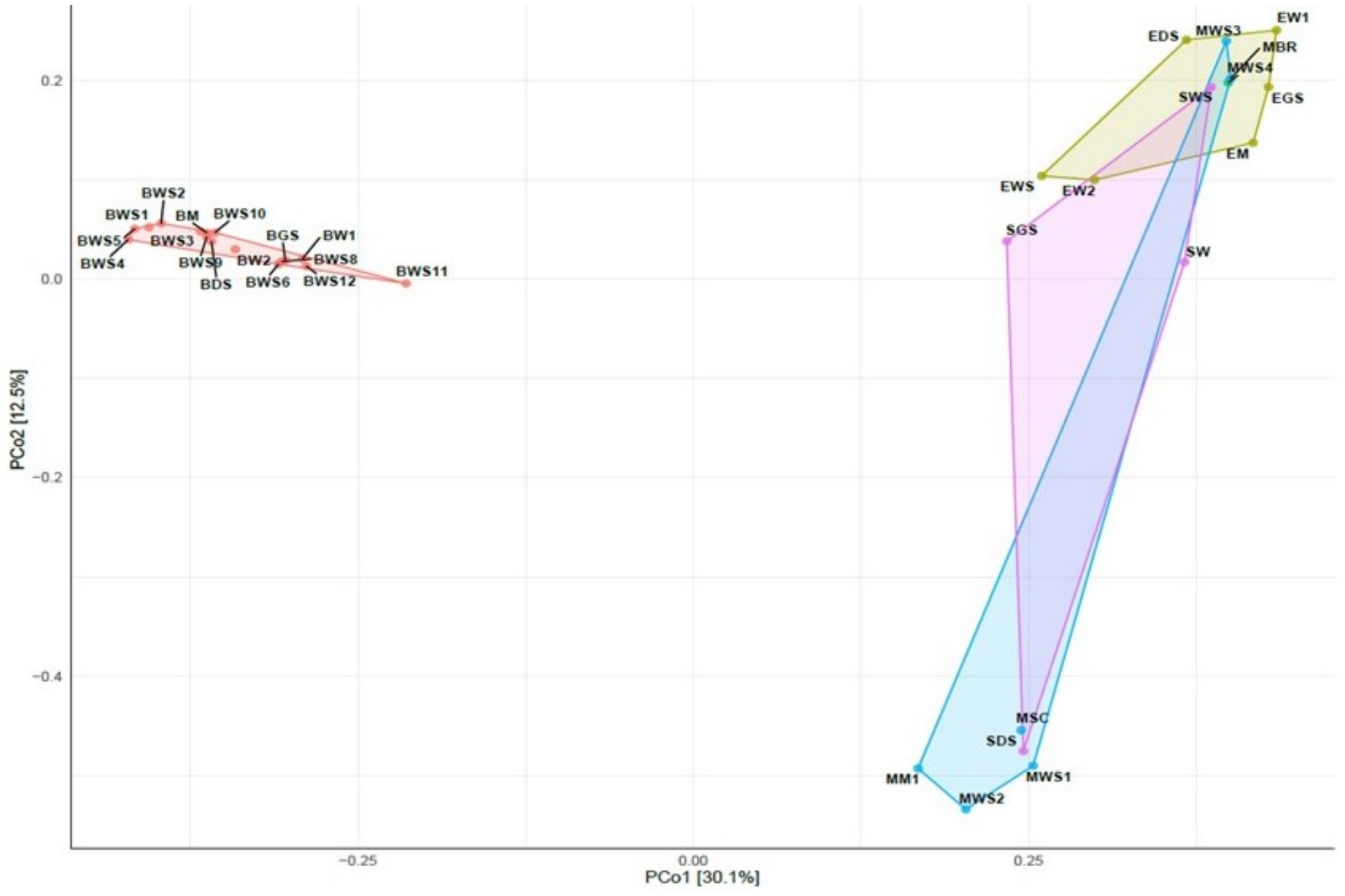


Figure 4

Bray Curtis dissimilarity analysis showing samples clustering 